\title{
CRITICAL NOTICE
}

Hume's System: An Examination of the First Book of His Treatise, by David Pears. New York: Oxford University Press, 1990. Reviewed by David A. Reidy, Jr., University of Kansas.

In his recent book, Hume's System: An Examination of the First Book of his Treatise, David Pears presents David Hume not as the radical skeptic many have thought him to be, but rather as a "cautious naturalist" and a "sophisticated empiricist," a philosopher willing to give his epistemological stamp of approval to many of the "audacious inferences" ubiquitous in both science and everyday life, but unwilling, because, in the end, unable, to justify those inferences, save by appeal to naturalistic justifications. Pears likens Hume in this regard to Wittgenstein, noting that both acknowledged and accepted the necessity, in the final analysis, of a naturalistic justification for foundational epistemological claims. For Hume, an adequate, rational (and empirical) analysis of the reasoning human beings successfully use to map, manipulate and predict the world that spatially and temporally surrounds them must appeal to both nature and mind.

If, in writing this book, Pears aimed, among other things, to sensitize readers to the limited and subtle nature of Hume's so-called skepticism, he succeeds for the most part. Pears portrays Hume as a philosopher in search of the psychological analog to Newton's Principia, a philosopher committed to discovering the "secret springs and principles" of human reasoning through an "experimental moral philosophy." Hume is, consequently, no general skeptic. His acknowledgement that it may be impossible to explain foundational principles of human thought in terms of reason makes him no more a skeptic than Newton's acknowledgement that it may be impossible to rationally explain the fundamental forces in the universe makes Newton a skeptic (Treatise, xvi-xix). Nor, Pears suggests, is Hume, when carefully read, the sort of narrow skeptic others have sometimes portrayed him to be, reserving his skepticism for particular claims, for example, causal inferences. Unfortunately, Pears does not discuss whether Hume is a skeptic with respect to, not our knowledge, but rather our reason as a path to that knowledge, a possibility afforded by Hume's argument that reason leads one to reject the existence of external objects, a mistake that nature will not permit.

In this book, Pears aims to do more than reassess Hume's "skepticism." Several recent interpretations of Hume's work have, according to Pears, focused almost exclusively upon that strand of Hume's 
thought which addresses the nature of and evidence for certain beliefs, e.g., the belief that the red ball must move when the white ball strikes it. Pears finds these interpretations problematic, for he finds Hume's thought equally focused upon the meaning (and meaningfulness) of certain ideas supposed to participate in the content of these beliefs. To be sure, Pears notes that Hume himself did not always distinguish carefully between the analysis of a claim's meaning(fulness) and the nature of and evidence for a belief in its veracity. Nonetheless, he argues that the two strands of thought are present and logically separable. Because questions of meaning logically precede questions of truth and evidence, any careful presentation of Hume's thinking, Pears argues, ought to reveal Hume's analysis of the former before the latter, even if Hume did not. Consequently, Pears aims both to offer a "balanced" interpretation of Hume, one that gives equal time to questions of meaning and questions of truth and evidence, and to present always, with respect to the particular issues analyzed, Hume's thinking on the former question before the latter. For example, when examining Hume's account of memory, before presenting Hume's thinking on how humans come to believe memoryideas, Pears first attempts to extract from Hume's work an account of the meaningfulness of memory-ideas, as distinct from, say, meaningless daydreaming image-ideas. Perhaps not surprisingly, given this method, Pears finds that many of the difficulties Hume encounters in Book One of the Treatise stem from Hume's failure to address questions of meaning prior to questions of evidence.

Now, perhaps this approach is not fair to Hume. After all, it is quite possible, especially given Hume's heavy emphasis upon natural feelings and the role of images in human thought, that Hume found careful distinctions between questions of meaning and questions of truth unnecessary to his phenomenological and naturalistic study of human reasoning. Pears briefly considers this possibility but quickly dismisses it, arguing that had Hume found such distinctions unnecessary to his project, he was wrong.

Here Pears reveals his two basic assumptions about the nature of Hume's project. First, he reads Hume as a sort of proto-twentieth-century analytic philosopher struggling to achieve the clarity of later thinkers in that tradition. Consequently, Hume's failure to disentangle questions of meaning from questions of truth is inexcusable. Second, Pears takes Hume's allusions to Newton seriously. He assumes that Hume was attempting, in the Treatise, to outline a complete (and Newtonian) science of the mental world. Thus, for Pears, the fact that Hume excludes language from his study, focusing instead upon thought in and through images, dooms Hume to failure. 
Pears assumes, rather than arguing for, this particular view of Hume's project. To be sure, Book One of the Treatise, when read in isolation from the remainder of the Treatise and the two Enquiries, lends itself to Pears' view. Given this view, Pears' reading is careful, well-argued and thoughtprovoking. Nonetheless, one cannot help but wonder whether it is really "Hume's System" that Pears examines. Arguably, one cannot completely and accurately examine Hume's accounts of belief and thought in Book One of the Treatise without paying attention to Hume's accounts of sentiment and natural feeling. And yet this is what Pears attempts to accomplish.

Pears divides his book into two parts. In the first part, he briefly sketches Hume's theory of mind as it appears in Book One of the Treatise. Here Pears identifies and develops several almost thematic difficulties with Hume's thinking which, for Pears, seriously impoverish Hume's theory of mind. In the second part, Pears traces the application of Hume's theory of mind to three problems central to Book One of the Treatise: causation, personal identity and perception. Here Pears finds that, despite the "almost primitive" nature of Hume's theory of mind, Hume reaches profound insights regarding these three problems. With respect to each problem, Pears examines Hume's rejection of the "rationalist" and "naive empiricist" accounts, identifies what he takes to be the central weakness in Hume's own "sophisticated empiricist" account, traces that weakness back to one or more of the thematic weaknesses of Hume's theory of mind developed in Part One, and then offers Hume a way out of his difficulty.

Pears begins Part One with Hume's maxim that all ideas originate in and are copies of impressions. Highlighting Hume's empiricism, Pears notes that the priority of impressions over ideas is not a logical priority, but rather a matter of contingent fact which Hume claims to discover through observation. Pears argues that like Russell's principle of acquaintance, Hume's maxim, in conjunction with an atomistic analysis, identifies and sets aside spurious ideas and meaningless claims. For example, Hume argues that the idea of the self as the vessel or substance unifying the sequence of impressions present to experience is meaningless for there is no, and could be no, impression from which such an idea would originate.

But, Pears notes, Hume's maxim entails more than a theory of meaning and it would be a mistake to reduce it to such. For example, it does not isolate and set aside as spurious the free-floating (and semantically meaningless) image-ideas of day-dreaming. Hume's maxim merely identifies those entities in terms of which mental phenomena must be understood. For Hume, then, ideas occur sometimes as less than, sometimes just as and sometimes as more than "meaning-bearers." For example, the idea of a particular shade of blue may occur as a day- 
dreaming image; or, as a meaning-bearing idea, as when I wonder whether a particular neck-tie is blue; or, as part of a judgment or belief, as when I conclude that the neck-tie is indeed blue. Pears argues that a central weakness of Hume's theory of mind is just this failure to distinguish systematically between the occurence of ideas as mere data, as "meaningbearing" entities and as part of the content of beliefs or judgments. For Hume, the "content" of the idea in each case remains unchanged.

Pears argues that this initial failure to distinguish the various ways in which ideas occur weakened Hume's overall theory of mind, as well as his detailed explanations of causal inference, personal identity and perception. For example, it forced Hume to argue that an idea occuring as the content of a belief differs from the same idea occuring outside the belief context only in the "manner" in which it presents itself to the mind, a notion, Pears notes, which Hume had great difficulty explicating. Had Hume initially distinguished between the various ways in which ideas occur in mental phenomena, he would have produced, Pears argues, a more sophisticated, complete and fertile theory of mind. Specifically, Pears suggests, had Hume reflected upon beliefs, he would have realized that beliefs persist through time and influence action, unlike passing thoughts or day-dreaming images. In other words, had Hume been more careful, he would have noticed the uniquely dispositional nature of beliefideas and analyzed them accordingly.

But here Pears seems to miss a part of Hume's system. Pears is correct, to be sure, that Hume apparently understands "belief" as a passive mental event. But this does not explain why Hume appears untroubled in the Treatise by his remark to the effect that while he could not exactly explicate what he meant by the "manner" in which a belief-idea forces itself upon a mind, he was certain that his readers would know to what he was referring (Treatise, 106, 624). Hume could say this without apparent difficulty, in large part, because for Hume the "peculiar something" which attends to belief-ideas and distinguishes them from other ideas is a "natural" feeling, a force, perhaps unexplainable through reason, naturally present in all human minds. That Pears interprets Hume's inability to explicate in detail that which distinguishes belief-ideas from other ideas as a "failure of the science of the human mind" from which Hume must be saved (Pears, 50) evidences both Pears' unargued for understanding of Hume's project and his insensitivity to the possibility that Hume is genuinely skeptical about reason itself. Pears never really reflects on why Hume indeed may not have been troubled by his inability to explicate more fully the peculiar nature of beliefs. Instead he uses this inability primarily as a springboard from which to leap to twentiethcentury issues. 
A second and related weakness of Hume's theory of mind which Pears develops focuses upon Hume's "atomism." For Hume, a simple idea, like a simple impression, is that which cannot be further divided. For example, both the impression and subsequently formed idea of the taste of a particular orange are simple. Complex ideas either copy complex impressions (the shape, color and smell of the orange united in one impression) or arise (a "vertical" movement) from the conjunction of simple ideas (which copy simple impressions). Pears analogizes this "atomistic" tendency in Hume's thinking to Russell's logical atomism and Wittgenstein's early work. Like Russell and early Wittgenstein, however, by focusing exclusively upon the intrinsic features of impressions and ideas and thereby cutting himself off from their extrinsic features (including lateral relations among them), Hume finds himself unable to explain certain phenomena.

Indeed, Hume confesses his inability to explain an individual's ability to form, without a prior impression, the idea of a particular shade of blue missing from an appropriately formed color wheel of various shades of blue. Hume, however, simply dismisses this objection to his maxim. Dissatisfied, Pears offers Hume a way out of this difficulty. Pears suggests that Hume allow for certain ideas to be derived from impressions in ways other than copying and conjoining; specifically, they may be derived horizontally from the lateral, extrinsic relations among impressions. To save his empiricism, Pears argues, Hume must sacrifice his strict atomism.

Now, the value of Pears' contribution to Hume's thought here notwithstanding (Hume does need some way, consistent with his maxim, to explain the origin of ideas such as "betweenness"), it is unfortunate that again Pears fails to reflect on why Hume would dismiss this obvious objection to his maxim so easily. Pears misses a real opportunity to reflect on Hume's system. Instead, Pears moves directly on to solving the problem with Hume's thought.

It is also unfortunate that Pears does not reflect upon how his proposed solution to Hume's missing shade of blue problem might alter the Humean understanding of "experience." For Hume, phenomenological simples ultimately constitute experience. Hume presumably arrived at this view empirically. Pears is unclear about whether his solution to Hume's missing shade of blue problem entails a broader understanding of experience, one in which "relational properties" simply present themselves to the mind as fundamental constituents of experience. If so, Pears, perhaps, comes too close to sacrificing Hume's particular brand of empiricism to avoid the obligation to provide a more detailed analysis on this point than he provides. 
A third weakness in Hume's thinking related to both his failure to distinguish between the various modes in which ideas occur and his atomism is, for Pears, Hume's tendency to assimilate the active, purposeful, and directed thinking that takes place when one forms a judgment to the passive, non-directed thinking that takes place when one merely entertains a notion. For example, this failure to distinguish between active and passive thought made it difficult for Hume to articulate a coherent account of memory and imagination. Pears notes that Hume, at the outset, is not clear whether he means for "memory" to refer to an activity of the mind (remembering) or to the content of an idea passively present to the mind (a memory). Hume's account of memory fails, Pears argues, as an explanation of the sort of directed thought which takes place when one purposefully recollects a particular event. The only plausible distinction between the memory-idea present to my mind in such a case and an otherwise identical imagination-idea is that the former actually refers to some past impression or idea of mine while the latter does not. For Hume, however, it will often be the case that both the memory-idea and the imagination-idea are simple and unanalyzeable, making it impossible to explain why a memory-idea refers while an imagination-idea does not. Again, Pears suggests, the "primitive" nature of Hume's theory forces Hume to rely upon almost unintelligible notions such as force and vivacity.

This failure to incorporate into his theory of mind this distinction between active and passive thought also weakened Hume's analysis of general, abstract ideas. Hume argued that a general, abstract idea, say of a triangle, must acquire its generality from the "term" to which it attaches, for example, the word "triangle," because the idea-image present to the mind will be always of a particular triangle, as it is impossible for the mind to have had an impression of a general and abstract triangle, and any particular idea-image may support multiple general significations. Pears, quite correctly, notes that Hume does not explain here the difficult nature of general, abstract ideas; he merely displaces it. Hume does not explain how the term "triangle" signifies the generality of an abstract idea. Pears does not find this surprising. He argues that any such explanation must refer to intentions, and Hume's tendency to understand thinking as a passive rather than active process (as well as Hume's atomism) makes it unlikely Hume will offer such an explanation.

Because Pears finds Hume tacitly relying throughout his theory of mind upon unexamined features of language (e.g., reference and intentionality), Pears claims that the best interpretive strategy when reading Hume is to be ready to make the adjustments to Hume's theory necessary to save as much of his thought as possible. Pears does not ask 
whether, if pressed, Hume might not have conceded tacit reliance upon unexamined features of language and argued that such reliance was not particularly relevant to his project, a question perhaps necessary to an "examination" of "Hume's System." If Hume intended only to articulate the philosophical foundations of a science devoted to explaining mental phenomena as events analogous to physical events (i.e., they just happen), perhaps noting that general ideas receive their generality from the terms to which they attach sufficiently explains such ideas. As Pears himself notes, Hume's object of study was thought as an observable event, not language. While Pears and contemporary readers may recognize the inseparability of thought and language, it is, perhaps, unfair to demand that Hume recognize this too. In any event, Pears aims in his reading of Hume's accounts of causal inference, personal identity and perception to first indicate the impressive ground Hume was able to cover with his "primitive" theory of mind and then, utilizing the resources now available to analytic philosophy, to "save" as much of Hume's account of each problem as possible.

Hume notes correctly the gap between the evidence for and content of causal inferences. Hume, however, distinguishing himself from earlier thinkers, did not try to close that gap. Rather, he explains our movement from evidence to causal belief in naturalistic terms.

The evidence in support of a causal inference never exceeds impressions, specifically the constant conjunction of impressions related by resemblance and contiguity. Despite this meager evidence, human beings routinely infer, when the red ball strikes the white ball, that the red ball must move. Hume rejects the "rationalist's" argument justifying such audacious inferences. A priori reasoning, being limited to the relations among ideas (all of which originate in impressions), cannot account for the "audacious" causal inferences human beings routinely make (the content of which exceeds the impossibility of mountains without a valley). Hume also rejects the "naive empiricist's" argument that causal inference rests upon the impression of causal necessity at work in either the physical or mental world. Hume simply finds no such impression.

Pears finds Hume's arguments against rationalism and naive empiricism compelling. As an aside, Pears notes that Hume does not therefore deserve the label skeptic. Indeed, from Hume's side, it is the rationalist and naive empiricist that deserve that label, for they require belief in something never available to the human mind. Pears does not find as compelling, however, Hume's own constructive account of causal inference.

For example, Pears argues that Hume fails to explain how one could believe a hypothetical causal statement. A hypothetical causal statement 
will always lack a present impression from which it can derive the vivacity necessary, on Hume's account, for belief-status. Hume also fails, Pears argues, to explain the ability to review rationally one's causal inferences, adjusting inferences to the available evidence. Both difficulties stem from Hume's tendency to disregard purposeful, directed thought in favor of passive thought.

Hume's constructive account suffers, according to Pears, from more serious defects, however. Hume argues that the idea of causal necessity is derived from an internal impression of the constraint or necessity attendant to the mind's determinations as it, relying upon the "associative track" laid down by the constant conjunction of impressions of type A with impressions of type B, infers from the appearance of an impression of type A the subsequent appearance of an impression of type B. Pears notes that many have struggled to make sense of this "internal impression of necessity." Stroud, for example, argues that the notion cannot be explicated. The idea and impression of necessity each appear to derive their respective identity and content from the other.

Indeed Hume does appear to be in trouble here. On the one hand, Hume finds no simple impression "of necessity," as either a mental or physical phenomena. On the other hand, Hume does identify a "feeling" of constraint attendant to causal inference; he recognized a difference between guessing and inferring. Hume's resources, however, specifically his maxim and atomism, Pears argues, simply left him unable to explicate from that "feeling" the origin of a meaningful idea of causal necessity. Unable to dismiss Hume's "internal impression of necessity" as hopelessly meaningless, Pears sets out to save as much of this notion as possible.

Pears argues that Hume should not have set out to locate the origin of the idea of causal necessity in a simple impression of necessity, as if he were searching for the origin of the idea of a particular shade of blue in an impression of a particular shade of blue. Unlike the idea of a particular shade of blue, the idea of causal necessity is relational. Hume should have seen this, Pears argues, because the "feeling" of constraint Hume identifies is a relational property involving propositions and our attitudes toward them in specific contexts, specifically, the "powerlessness" of the will in certain contexts in relation to the propositional content of causal inferences. To make sense of the idea of necessity (like the idea of the shade of blue missing from the color wheel), Pears argues, Hume must allow that certain ideas originate horizontally from extrinsic and lateral relations among impressions.

Overall, although weighed down by excessive listing and repetition, Pears' book is carefully written. He protects well his interpretation of Hume and his arguments on particular issues throughout. As a bridge 
between Hume and twentieth-century analytic philosophy, the book works reasonably well. Unfortunately, the book brings Hume into the twentiethcentury to the almost complete exclusion of taking the twentieth-century reader back to Hume. 